This item was submitted to Loughborough's Research Repository by the author.

Items in Figshare are protected by copyright, with all rights reserved, unless otherwise indicated.

\title{
Application of smoothed particle hydrodynamics in analysis of shaped- charge jet penetration caused by underwater explosion
}

PLEASE CITE THE PUBLISHED VERSION

https://doi.org/10.1016/j.oceaneng.2017.08.057

\section{PUBLISHER}

(C) Elsevier

\section{VERSION}

AM (Accepted Manuscript)

\section{PUBLISHER STATEMENT}

This work is made available according to the conditions of the Creative Commons Attribution-NonCommercialNoDerivatives 4.0 International (CC BY-NC-ND 4.0) licence. Full details of this licence are available at: https://creativecommons.org/licenses/by-nc-nd/4.0/

\section{LICENCE}

CC BY-NC-ND 4.0

\section{REPOSITORY RECORD}

Zhang, Zhifan, Longkan Wang, Furen Ming, Vadim V. Silberschmidt, and Hailong Chen. 2019. "Application of Smoothed Particle Hydrodynamics in Analysis of Shaped-charge Jet Penetration Caused by Underwater Explosion". figshare. https://hdl.handle.net/2134/27984. 


\title{
Application of Smoothed Particle Hydrodynamics in analysis of shaped-charge jet penetration caused by underwater explosion
}

\author{
Zhifan Zhang $^{\text {a,b,c }}$, Longkan Wang ${ }^{\mathrm{d}}$, Furen Ming ${ }^{\mathrm{b}, *}$, Vadim V. Silberschmidt ${ }^{\mathrm{c}}$, Hailong Chen ${ }^{\mathrm{b}}$ \\ ${ }^{\text {a }}$ State Key Laboratory of Explosion Science and Technology, Beijing Institute of Technology, Beijing 100081, China \\ ${ }^{\mathrm{b}}$ College of Shipbuilding Engineering, Harbin Engineering University, Harbin 150001, China \\ ${ }^{c}$ Wolfson School of Mechanical, Electrical and Manufacturing Engineering, Loughborough University, Leicestershire LE11 $3 T U$, UK \\ ${ }^{\mathrm{d}}$ China Ship Research and Development Academy, Beijing 100101, China
}

A B S T R A C T

\begin{abstract}
A process of target penetration by a shaped-charge jet includes three main stages: charge detonation, formation of a metallic jet and its penetration of the target. With continuously increasing computational power, a numerical approach gradually becomes more prominent (combined with experimental and theoretical methods) in investigations of performance of a shaped-charge jet and its target penetration. This paper presents a meshfree methodology - Smoothed Particle Hydrodynamics (SPH) - for a shaped charge penetrating underwater structures. First, a SPH model of a sphere impacting a plate is developed; its numerical results agree well with the experimental data, verifying the validity of the mentioned developed method. Then, results obtained for different cases for various materials of explosives and liners - are discussed and compared, and as a result, more suitable parameters of the shaped charge in order to increase the penetration depth are obtained - HMX and copper were chosen respectively as the explosive and the liner material. It follows by validation of a model of a free-field underwater explosion, developed to verify the effectiveness of the modified SPH method in solving problems of underwater explosion; its numerical results are compared with an empirical formula. Finally, the SPH method is applied to simulate the entire process ranging from the detonation of the shaped charge to the target penetration employing the optimal parameters. A fluid around the shaped charge is included into analysis, and damage characteristics of the plate exposed to air and water on its back side are compared.
\end{abstract}

\author{
Keywords: \\ $\mathrm{SPH}$ \\ Metal jet \\ Underwater explosion \\ Penetration
}

\section{Introduction}

A strong discontinuous shock wave (Ming et al., 2016; Zhang et al., 2011; Kim and Shin, 2008; Rajendran and Narasimhan, 2001, 2006; Ghoshal and Mitra, 2016; Hung et al., 2005, 2009; Zhang et al., 2015a; Zhang and Liu, 2015) and a high-speed metal jet (Arnold and Rottenkolber, 2013; Feng et al., 2013; Liu et al., 2003; Molinari, 2002; Katayama and Kibe, 2001; Katayama et al., 2001; Chen and Liu, 2012; Yang et al., 2016; Baêta-Neves and Ferreira, 2015; Miyoshi, 2008) can be generated by a shaped charge associated with underwater explosion, which can cause damage in structures. In researches of a shock wave caused by underwater explosion, Zhang et al. (Ming et al., 2016; Zhang et al., 2011). presented its numerical and experimental analysis together with that of structure destruction. Rajendran and Narasimhan (2006, 2001) carried out a series of experiments to study damage characteristics of plates subjected to underwater explosion. Hung et al. (2005, 2009). provided an experimental investigation of a dynamic response of a structure subjected to underwater explosion. Although experimental research (Zhang et al., 2013, 2015b; Yin et al., 2016; Li et al., 2016; Han et al., 2016) is the most effective and direct method to investigate underwater explosions and their cumulative effect, it has some disadvantages: higher risk to human operators, non-repeatability and limited information acquisition. Therefore, a numerical method and theoretical analysis are usually combined with experiments to study the related load characteristics.

For analysis of a shaped charge, Liu et al. (Feng et al., 2013; Liu et al., 2003). developed two different models of a shaped-charge jet - with and without a charge - and studied the process of jet formation using a Smoothed Particle Hydrodynamic (SPH) scheme. Molinari (2002) presented a finite-element simulation of formation and fragmentation of a shaped-charge jet and its penetration in a plate. Katayama et al. (Katayama and Kibe, 2001; Katayama et al., 2001). proposed a numerical 
analysis method to simulate the jet-formation and penetration processes for a conically shaped charge. However, few published papers discussed a damage response of a steel plate to a shaped-charge jet associated with an underwater explosion. Computational difficulties caused by mesh distortion when using a finite-element method can be overcome by employing the SPH method since it is suitable for solving problems with large deformations thanks to its mesh-less nature; besides, its Lagrangian formulation makes it easy to capture material interfaces. Whereas the standard SPH method had poor performance in solving problems with a large density ratio (Liu and Liu, 2010), it could be modified to avoid the distortion of physical quantities.

In this paper, a modified SPH method based on volume approximation is utilized to simulate the formation of a metal jet and its target penetration. First, after a brief discussion of SPH, different material models used in the developed SPH model are established to analyse a metal-jet velocity and a penetration depth for the target. A cylindrically shaped charge surrounded by a spherical-segment liner is presented in the model. Three types of explosives are chosen - TNT, Composition B and HMX; as for the liner, three kinds of materials were employed aluminium, copper and steel. After that, results obtained for different cases are discussed and compared, and as a result, more suitable parameters of the shaped charge are obtained. Finally, an SPH model with optimal parameters is developed to simulate the entire process of charge detonation, jet formation and its penetration into an underwater structure. Further, damage from a shock wave and the metal jet on the plate are analysed in detail. In addition, different cases of the plate exposed to air and water on its back side are discussed.

\section{Theoretical background and numerical method}

\subsection{Basic features of $S P H$}

The SPH method (Ming et al., 2016; Feng et al., 2013; Liu et al., 2003; Liu and Liu, 2010; Zhang et al., 2012; Swegle and Attaway, 1995; Colagrossi and Landrini, 2003; Liu and Liu, 2003; Zhang et al., 2015c, 2017a; Sun et al., 2017; Sun et al., 2016; Zhang et al., 2017b; Dobratz, 1981) provides an advantage of an accurate shock capturing thanks to its Lagrangian nature and of a mesh-less character shown to be very efficient in modelling of underwater explosions and accurate in capturing evolution of a metal jet with its large deformations. Two key steps are included in the formulation of SPH approximations - kernel and particle approximations (Liu and Liu, 2003). For kernel approximation, a field function $f(x)$ is described as integral representation in a continuous form using a kernel or smoothing function, given by (Liu and Liu, 2003)

$$
\langle f(\boldsymbol{x})\rangle=\int_{\Omega} f\left(\boldsymbol{x}^{\prime}\right) W\left(\boldsymbol{x}-\boldsymbol{x}^{\prime}, h\right) d \boldsymbol{x}^{\prime},
$$

where $\langle f(x)\rangle$ is the approximated value; $W$ is the smoothing function representing a weighted contribution; $h$ is the smooth length; $\boldsymbol{x}$ is the position vectors of the particles.

Subsequently, a computational domain is discretized with a set of particles. As for particle approximation, the field function $f(x)$ and its derivative $\nabla f(x)$ are approximated as weighted sums over surrounding particles within the support domain, expressed as (Liu and Liu, 2003)

$$
\begin{aligned}
& \left\langle f\left(\boldsymbol{x}_{i}\right)\right\rangle=\sum_{j=1}^{N} \frac{m_{j}}{\rho_{j}} f\left(\boldsymbol{x}_{j}\right) W_{i j}, \\
& \left\langle\nabla \cdot f\left(\boldsymbol{x}_{i}\right)\right\rangle=\sum_{j=1}^{N} \frac{m_{j}}{\rho_{j}} f\left(\boldsymbol{x}_{j}\right) \cdot \nabla_{i} W_{i j},
\end{aligned}
$$

where $\left\langle f\left(\boldsymbol{x}_{i}\right)\right\rangle$ is the approximated value for particle $i$; $N$ is the number of particles in the support domain; $m$ and $\rho$ denote the mass and density, respectively; $W_{i j}$ is the smoothed function of a pair of particles $i$ and $j$ (the cubic spline function is employed in this paper).

Combined with Navier-Stokes equations applied for hydrodynamics of fluids and solids with material strength, standard discretized equations of an SPH particle approximation for the continuity, momentum and energy equations can be found in Liu and Liu (2003).

\subsection{Modified equations}

The standard SPH method is believed to have poor performance in solving problems with a large density ratio (Liu and Liu, 2010; Ming et al., 2017). To avoid the distortion of physical quantities, the modified SPH method (Zhang et al., 2015c) was applied based on volume approximation in simulations of a shaped-charge jet associated with underwater explosion. The conservation of mass, momentum and energy in SPH as well as the motion equation can be expressed as

$$
\left\{\begin{array}{l}
\frac{d \rho_{i}}{d t}=\rho_{i} \sum_{j=1}^{N} \frac{m_{j}}{\rho_{j}}\left(\boldsymbol{v}_{i}-\boldsymbol{v}_{j}\right) \cdot \nabla_{i} W_{i j} \\
\frac{d \boldsymbol{v}_{\mathbf{i}}}{d t}=-\sum_{j=1}^{N} \frac{m_{j}}{\rho_{j}}\left(\frac{\boldsymbol{\sigma}_{\mathbf{i}}+\boldsymbol{\sigma}_{j}}{\rho_{i}}+\Pi_{i j}\right) \nabla_{i} W_{i j} \\
\frac{d e_{i}}{d t}=\frac{1}{2} \sum_{j=1}^{N} \frac{m_{j}}{\rho_{j}}\left(\frac{\boldsymbol{\sigma}_{i}+\boldsymbol{\sigma}_{\mathbf{j}}}{\rho_{i}}+\Pi_{i j}\right)\left(\boldsymbol{v}_{i}-\boldsymbol{v}_{j}\right) \cdot \nabla_{i} W_{i j} \\
\frac{d x_{i}}{d t}=\boldsymbol{v}_{i}
\end{array}\right.
$$

where $\boldsymbol{v}, e, t, \boldsymbol{x}, \boldsymbol{\sigma}$ denote the velocity, energy, time, coordinates and stress, respectively; $W_{i j}=W\left(\boldsymbol{x}_{i}-\boldsymbol{x}_{j}, h\right)=W\left(\left|\boldsymbol{x}_{i}-\boldsymbol{x}_{j}\right|, h\right)$ is the smoothed function of a pair of particles $i$ and $j$ (the cubic spline function is applied in this paper); $r_{i j}$ defines the distance between particles $i$ and $j ; \nabla_{i} W_{i j}=$ $\frac{x_{i}-x_{j}}{r_{i j}} \frac{\partial W_{i j}}{\partial r_{i j}}=\frac{x_{i j}}{r_{i j}} \frac{\partial W_{i j}}{\partial r_{i j}} ; \Pi_{i j}$ is the artificial viscosity (Liu and Liu, 2003).

\subsection{Constitutive model}

(1) Stress $\sigma$ for fluids is composed of two terms: isotropic pressure $P$ and viscous shear stress $\tau$ (Liu and Liu, 2003). Since the level of viscosity is small, it can be ignored in analysis of strong impacts such as a case of a shaped-charge jet associated with underwater explosion. The pressure $P$ can be obtained from an equation of state (EoS).

Here, the Jones-Wilkins-Lee (JWL) EoS (Dobratz, 1981) is used for detonation products, because explosive gas with high temperature and high pressure is generated after explosive initiation, expressed as

$P=A\left(1-\frac{\omega \eta}{R_{1}}\right) e^{-\frac{R_{1}}{\eta}}+B\left(1-\frac{\omega \eta}{R_{2}}\right) e^{-\frac{R_{2}}{\eta}}+\omega \eta \rho_{0} e$,

where $\rho_{0}$ and $e$ denote the initial density and the specific internal energy per unit mass; $A, B, R_{1}, R_{2}$ and $\omega$ are the experimental fitting coefficients; $\eta$ is the ratio of the density of detonation products to the initial density of the original explosive. Parameters of the EoS used in simulations are listed in Table 1.

Since water is highly compressed during the process of underwater explosion, a state equation fit for high-pressure conditions should be used. According to its different states, a Mie-Gruneisen equation of state (Steinberg, 1987) can be employed for water:

(a) In expansion state $(\mu<0)$

$p=\rho_{0} C_{0}^{2} \mu+\left(\gamma_{0}+a \mu\right) e$,

(b) In compressive state $(\mu>0)$ 
Table 1

Parameters of Jones-Wilkins-Lee Eos for explosive gas (Dobratz, 1981).

\begin{tabular}{|c|c|c|c|c|c|c|c|}
\hline Materials & $\rho_{0}\left(\mathrm{~kg} / \mathrm{m}^{3}\right)$ & $A(\mathrm{~Pa})$ & $B(\mathrm{~Pa})$ & $R_{1}$ & $R_{2}$ & $\omega$ & $e(\mathrm{~J} / \mathrm{kg})$ \\
\hline TNT & 1630 & $3.74 \times 10^{11}$ & $3.75 \times 10^{9}$ & 4.15 & 0.90 & 0.35 & $6.00 \times 10^{6}$ \\
\hline Composition B & 1717 & $5.24 \times 10^{11}$ & $7.68 \times 10^{9}$ & 4.20 & 1.10 & 0.34 & $8.50 \times 10^{6}$ \\
\hline HMX & 1891 & $7.78 \times 10^{11}$ & $7.07 \times 10^{9}$ & 4.20 & 1.00 & 0.30 & $1.05 \times 10^{7}$ \\
\hline
\end{tabular}

Table 2

Parameters of Mie-Gruneisen EoS for water (Steinberg, 1987).

\begin{tabular}{llllllll}
\hline$\rho_{0}\left(\mathrm{~kg} / \mathrm{m}^{3}\right)$ & $C_{0}(\mathrm{~m} / \mathrm{s})$ & $\gamma_{0}$ & $a$ & $S_{1}$ & $S_{2}$ & $S_{3}$ & $e(\mathrm{~J} / \mathrm{kg})$ \\
\hline 998 & 1480 & 0.5 & 0 & 2.56 & 1.986 & 1.2268 & 357.1 \\
\hline
\end{tabular}

Table 3

Parameters of Mie-Gruneisen EoS for aluminium, copper and steel (Allahdadi et al., 1993).

\begin{tabular}{llllll}
\hline Material & $\rho_{0}\left(\mathrm{~kg} / \mathrm{m}^{3}\right)$ & $\Gamma$ & $C_{s}(\mathrm{~m} / \mathrm{s})$ & $S_{s}$ & $e(\mathrm{~J} / \mathrm{kg})$ \\
\hline Aluminium & 2785 & 2.0 & 5328 & 1.338 & 0 \\
Copper & 8960 & 2.0 & 3940 & 1.489 & 0 \\
Steel & 7890 & 1.587 & 3075 & 1.294 & 0 \\
\hline
\end{tabular}

$p=\frac{\rho_{0} C_{0}^{2} \mu\left[1+\left(1-\frac{\gamma_{0}}{2}\right) \mu-\frac{a}{2} \mu^{2}\right]}{\left[1-\left(S_{1}-1\right) \mu-S_{2} \frac{\mu^{2}}{\mu+1}-S_{3} \frac{\mu^{3}}{(\mu+1)^{2}}\right]^{2}}+\left(\gamma_{0}+a \mu\right) e$,

where $\rho_{0}, C_{0}, a, e$ and $\gamma_{0}$ denote the initial density, the sound velocity, the volume correction coefficient, the specific internal energy per unit volume and Gruneisen coefficient; $S_{1}, S_{2}$ and $S_{3}$ are the fitting coefficients; $\mu$ is the compression ratio: $\mu=\eta-1$, where $\eta$ is the ratio of density before and after the explosion. Parameters of this EoS are listed in Table 2.

(2) Stress $\sigma$ for solids can be decomposed into two terms: the isotropic pressure $P$ and the deviatoric stress tensor $S$. The pressure $P$ can be obtained by solving the equation of state.

The Mie-Gruneisen EoS for solid materials is introduced as (Allahdadi et al., 1993)

$P=\left(1-\frac{1}{2} \Gamma \eta\right) \cdot\left(\alpha \eta+\beta \eta^{2}+\gamma \eta^{3}\right)+\Gamma \rho e$,

where $\Gamma$ and $e$ denote the Gruneisen parameter and initial energy, respectively; $\quad \alpha=\rho_{0} C_{s}^{2}, \quad \beta=\alpha\left[1+2\left(S_{s}-1\right)\right]$ and $\gamma=\alpha\left[2\left(S_{s}-1\right)+3\left(S_{s}-1\right)^{2}\right]$, where $C_{s}$ and $S_{s}$ denote the linear participation coefficient of the impact velocity and the velocity slope of particles; if $\eta<0, \beta=\gamma=0$. The respective parameters for aluminium, copper and steel, used in the current study, are listed in Table 3.

A shearing force in a metal liner with high shear strength should be taken into consideration in simulations. The deviatoric stress tensor $S$ can be obtained from the stress rate $\dot{S}$ by integration, while $\dot{S}$ can be gained from the Jaumann stress rate (Liu and Liu, 2003). The Johnson-Cook model (Johnson and Cook, 1983) was used to calculate yield strength, expressed as

$Y=\left[\sigma_{0}+B_{0} \varepsilon_{e}^{n}\right]\left[1+C \ln \left(\dot{\varepsilon}_{e} / \dot{\varepsilon}_{0}\right)\right]\left[1-\left(T^{*}\right)^{M}\right]$ where $\sigma_{0}, C$ and $M$ denote the static yield strength, strain-ratestrengthening coefficient and thermal-softening coefficient, respectively; $B_{0}$ and $n$ are the strain-hardening parameters; $\varepsilon_{e}$ is the equivalent plastic strain, i.e. $\varepsilon_{e}=2 \sqrt{3 I_{2}} / 3$ ( $I_{2}$ is the second invariant of the deviatoric stress tensor); $\dot{\varepsilon}_{e}$ and $\dot{\varepsilon}_{0}$ are the equivalent plastic strain rate and the reference strain rate, respectively; $T^{*}$ is the dimensionless temperature corresponding to the current level $T$, i.e. $T^{*}=\left(T-T_{r}\right) /\left(T_{m}-T_{r}\right)$, where $T_{r}$ is room temperature, $T_{m}$ is the melting point and $T=T_{r}+\left(e-e_{0}\right) /\left(M C_{v}\right)$, where $e, e_{0}$ and $C_{v}$ denote specific internal energy, initial specific internal energy and specific heat. The data for the Johnson-Cook model for aluminium, copper and steel are listed in Table 4.

In addition, steel was chosen as the target material. The JohnsonCook failure mode was used as the damage criterion. Due to a significant influence of a strain rate on its dynamic behavior, the fracture model is introduced. The damage parameter $D$ is given by (Johnson and Cook, 1985; Børvik et al., 1999)

$D=\frac{\Delta \varepsilon}{\varepsilon_{f}}$

where $\Delta \varepsilon$ and $\varepsilon_{f}$ denote the increment of equivalent plastic strain, which occurs during an integration cycle, and the equivalent strain to fracture, respectively.

The fracture occurs when $D=1.0$. The equivalent strain $\varepsilon_{f}$ can be expressed as (Johnson and Cook, 1985; Børvik et al., 1999)

$\varepsilon_{f}=\left[D_{1}+D_{2} \exp \left(D_{3} \sigma^{*}\right)\right]\left[1+D_{4} \ln \dot{\varepsilon}^{*}\right]\left[1+D_{5} T^{*}\right]$,

where $D_{1}, D_{2}, D_{3}, D_{4}$ and $D_{5}$ are the constants. The respective parameters for steel used in simulation are listed in Table 5.

\subsection{Treatment of multi-materials}

A slight penalty force of a Lennard-Jones model (Monaghan, 1994) is utilized to solve an interface problem, and the molecular force was so low that it just prevented particles' penetration. When the cutoff radius $r_{0}$ in the approach is greater or equal to the distance $r_{i j}$ between particles $i$ and $j$, particles on both sides of an interface tend to penetrate. Hence, as a results a molecular force acts on two approaching particles, described by

$\boldsymbol{F}_{i j}=f \cdot\left[\left(\frac{r_{0}}{r_{i j}}\right)^{a}-\left(\frac{r_{0}}{r_{i j}}\right)^{b}\right] \cdot \frac{\boldsymbol{x}_{i j}}{r_{i j}^{2}}$

where $f, a$ and $b$ are the set parameters.

Consequently, the ratio of $r_{0}$ to $r_{i j}$ was used to deal with the interface; this can guarantee good numerical stability without errors caused by the smoothing length. In addition, the leap-frog method is used as the timeintegrator (Liu and Liu, 2003). The fluid domain was considered to be big

Table 4

Parameters of Johnson-Cook constitutive model for aluminium, copper and steel (Johnson and Cook, 1983).

\begin{tabular}{|c|c|c|c|c|c|c|c|c|c|c|}
\hline Material & $\begin{array}{c}\sigma_{0} \\
(\mathrm{MPa})\end{array}$ & $\begin{array}{c}B_{0} \\
(\mathrm{MPa})\end{array}$ & $\begin{array}{c}\dot{\varepsilon}_{0} \\
\left(\mathrm{~s}^{-1}\right)\end{array}$ & $n$ & $C$ & $M$ & $\begin{array}{l}T_{m} \\
(\mathrm{~K})\end{array}$ & $\begin{array}{c}T_{r} \\
(\mathrm{~K})\end{array}$ & $\begin{array}{c}C_{v} \\
(\mathrm{~J} / \mathrm{kg} \cdot \mathrm{K})\end{array}$ & $\begin{array}{c}G \\
(\mathrm{GPa})\end{array}$ \\
\hline Aluminium & 265 & 426 & 1 & 0.34 & 0.015 & 1.0 & 775 & 288 & 875 & 27 \\
\hline Copper & 90 & 292 & 1 & 0.31 & 0.025 & 1.09 & 1356 & 288 & 383 & 45.4 \\
\hline Steel & 792 & 510 & 1 & 0.26 & 0.014 & 1.03 & 1793 & 288 & 477 & 77 \\
\hline
\end{tabular}


Table 5

Parameters of failure model for steel (Johnson and Cook, 1985; Børvik et al., 1999).

\begin{tabular}{llllll}
\hline Material & $D_{1}$ & $D_{2}$ & $D_{3}$ & $D_{4}$ & $D_{5}$ \\
\hline Steel & 0.05 & 3.44 & -2.12 & 0.002 & 0.61 \\
\hline
\end{tabular}

enough so that its boundaries will have an insignificant effect on damage characteristics.

\section{Numerical results and discussion}

\subsection{Influence of different materials on formation of metal jet}

\subsubsection{Numerical verification}

An Explosive Formed Projectile (EFP) could be formed after detonation of a shaped charge with a spherical-segment liner; here, the EFP was simplified as a metal sphere with a high speed. Hence, a validation model of a sphere impacting a plate was developed according to the description in (Hayhurst and Clegg, 1997), and its numerical results were compared with experimental data in order to verify the effectiveness of the modified SPH method. The comparison of results at about $6 \mu$ s is illustrated in Fig. 1 and Table 6. Apparently, the numerical results for the shape of the debris cloud have a good agreement with the experimental data in Fig. 1.

Additionally, it was found that the differences between debris-cloud velocities in the experiment (about 6.6, 6.4 and $4.9 \mathrm{~km} / \mathrm{s}$ ) and simulations (about 6.4, 6.3 and $5.0 \mathrm{~km} / \mathrm{s}$ ) (see Table 4) at different points are less than $4 \%$. Therefore, the closeness of numerical results with the experimental ones presented in (Hayhurst and Clegg, 1997) proved the effectiveness and accuracy of the presented SPH method in solution of the problems with high speeds and large deformations.

\subsubsection{Numerical model and parameters}

The validated model was subsequently used to simulate a shaped charge with a side length $h_{0}=40 \mathrm{~mm}$ and a diameter $D_{1}=30 \mathrm{~mm}$ with a cylindrical shaped charge having the curvature radius $r=17 \mathrm{~mm}$, surrounded by a liner with thickness $d=1 \mathrm{~mm}$. The length $h_{2}$ and the width $D_{2}$ of the target were $100 \mathrm{~mm}$ and $80 \mathrm{~mm}$, respectively. The distance $h_{1}$ between the charge and the target was about $20 \mathrm{~mm}$. A schematic of the problem with a coordinate system is shown in Fig. 2, with the detonation point coinciding with its origin point. The entire model was discretized with uniform particle spacing $d_{x}=0.2 \mathrm{~mm}$. The circular region in Fig. 2 represents the main research object of the target. The target is a solid block, made of steel; the detailed parameters can be found in Section 2.3.

Three types of explosives were chosen for our analysis - TNT, Composition B and HMX, denoted as Cases 1 to 3; as for the liner, three types of materials were used, namely, aluminium, copper and steel, corresponding to Cases 3 to 5 . In Cases 1 to 3, steel was used as the target
Table 6

Comparison of results for debris-cloud velocities at different points (Hayhurst and Clegg, 1997).

\begin{tabular}{llll}
\hline Axial Velocities $(\mathrm{km} / \mathrm{s})$ & Point 1 & Point 2 & Point 3 \\
\hline Experiment & 6.6 & 6.4 & 4.9 \\
Numerical method & 6.4 & 6.3 & 5.0 \\
\hline
\end{tabular}

material, with copper as the liner material. Combinations of explosives and a liner material used in the studied cases are listed in Table 7.

\subsubsection{Cases of different explosives}

In this section, the influence of different explosives on the metal-jet formation is discussed based on results obtained with the SPH method. The material of the liner was copper in all the cases. Due to a similar process of the formation, Case 3, i.e. HMX, is taken as an example.

The process of jet formation is illustrated in Fig. 3. The initial shape of the liner was a spherical segment as shown in (pos. 1) in Fig. 3. Large deformation of the liner was caused under the effect of the detonation wave in (pos. 2), with the velocity surging to about $3125 \mathrm{~m} / \mathrm{s}$. The figure also shows that the maximum velocity occurred at the centreline, i.e. at the axis of symmetry, at around $7 \mu$ s. Subsequently, due to the effect of pressure generated by the explosion gas around the liner, axial tension and radial compression of the metal liner were caused. Besides, the liner moved to this axis at extremely high momentum and energy. The liner was regarded as an elastic-plastic fluid since the stress level reached its yield strength, with the original outer surface turning into its inner surface. As a result, the metal jet with high energy and high speed was formed, with the original inner surface converted to its head. Meanwhile, the velocity peaked at about $3430 \mathrm{~m} / \mathrm{s}$ at around $11 \mu \mathrm{s}$ (pos. 3). After that, the velocity gradually diminished and dropped to around $3306 \mathrm{~m} / \mathrm{s}$ at about $15 \mu \mathrm{s}$. It is obvious that the metal jet elongated to several times of its initial length.

Evolution of the jet-head velocity with time is shown in Fig. 4. Three cases share the same tendency: the velocity increased at first and then decreased; it dramatically diminished after the jet arrived at the target. It can be found that the jet-head velocity in Case 3 was larger than that in two other cases, and, as a result, the jet reached the target earliest. The velocities in three studied cases peaked at $2680 \mathrm{~m} / \mathrm{s}, 3046 \mathrm{~m} / \mathrm{s}$ and $3430 \mathrm{~m} / \mathrm{s}$, respectively. It indicates that the HMX may have a higher damaging effect on the target. Besides, the jet-head velocity rapidly dropped because of the resistance effect of the target, stabilising finally, with a similar residual velocity for all the three cases at around $320 \mathrm{~m} / \mathrm{s}$.

To analyse the effect of the jet on the target, the dimensionless depth $D$ was introduced as the ratio of a penetration depth and the charge diameter. The penetration-depth curves are shown in Fig. 5. This depth increased with time, yet with the decreasing rate. Obviously, the depth in Case 3 was higher than that in two other cases. At around $60 \mu \mathrm{s}$, the
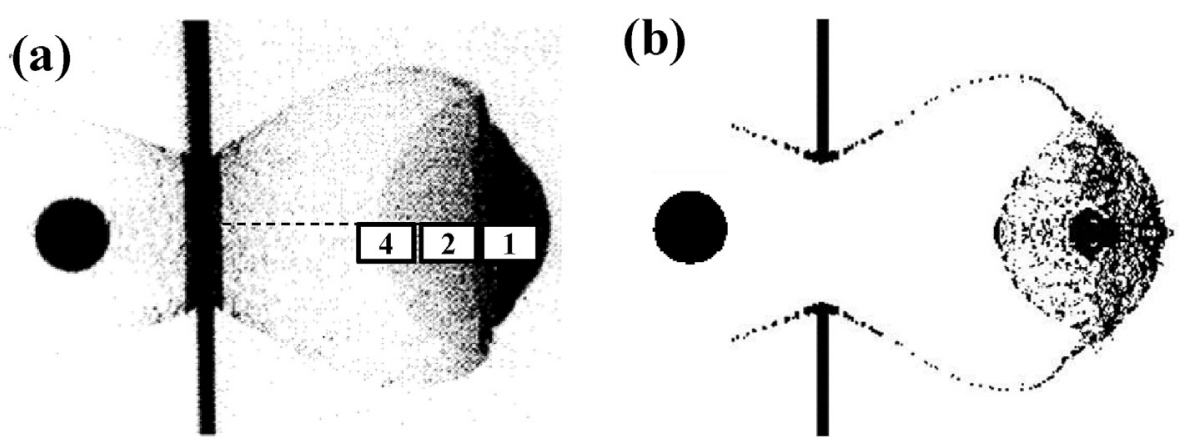

Fig. 1. Debris clouds at about $6 \mu \mathrm{s}$ : experimental (Hayhurst and Clegg, 1997) (a) and numerical results (b) (same length scale). 


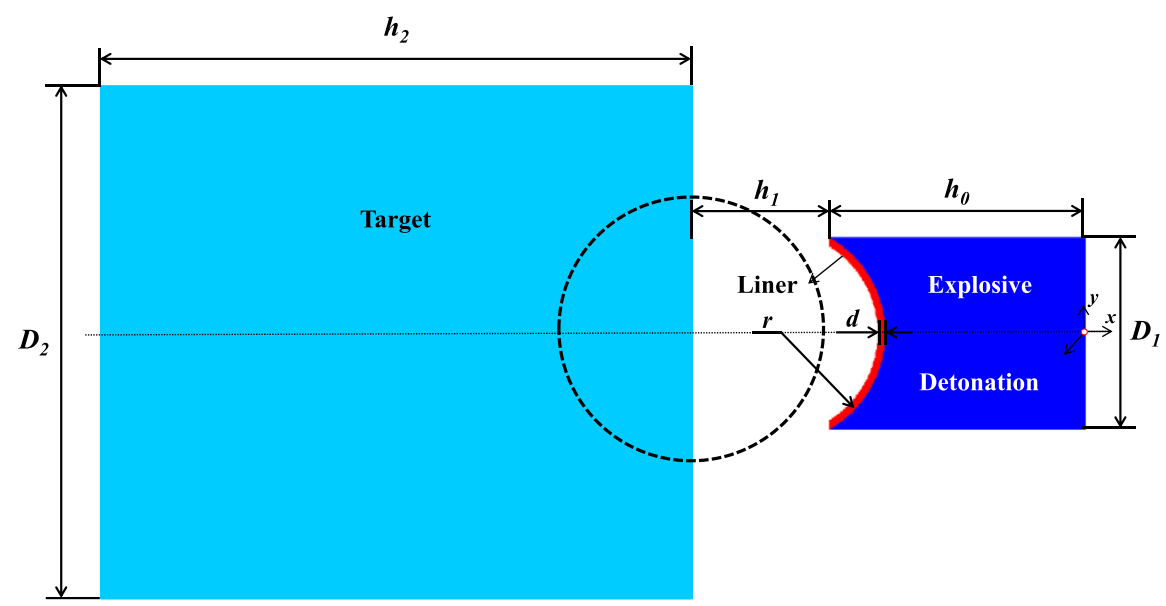

Fig. 2. Model of shaped charge and target.

residual velocities in three cases were almost the same (Fig. 4). At this moment, as can be found from Fig. 5, D was $0.79,0.89$ and 1.01, respectively, in Cases 1, 2 and 3. It is obvious that Case 3, i.e. with HMX explosive, resulted in a greater damage to the target.

\subsubsection{Cases of different liners}

Comparing three types of explosives, it was found that the damaging effect in Case 3 was the greatest; so, HMX was chosen as the explosive in this section. In addition, in order to investigate the influence of different liners on the cumulative effect, aluminium, copper and steel were used as liner materials. The comparison results for distributions of von Mises stress are illustrated in Fig. 6, where the circular region at the left represents the main research object as shown in Fig. 2 and the liner shape is

Table 7

Cases studies.

\begin{tabular}{lll}
\hline Case No. & Explosives & Liners \\
\hline 1 & TNT & Copper \\
2 & Composition B & Copper \\
3 & HMX & Copper \\
4 & HMX & Steel \\
5 & HMX & Aluminium \\
\hline
\end{tabular}

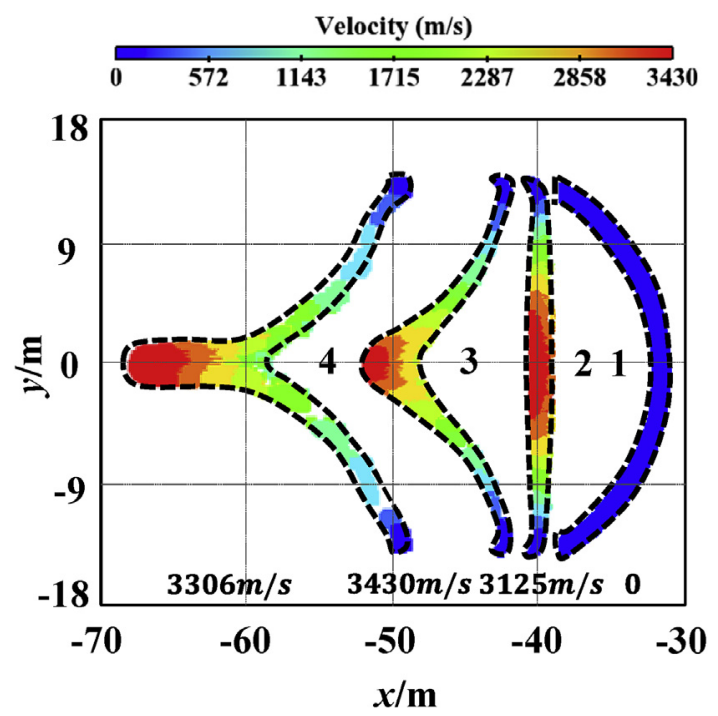

Fig. 3. Formation of metal jet after detonation at $t=0$ : (1) $0 \mu \mathrm{s}$; (2) $7 \mu \mathrm{s}$; (3) $11 \mu \mathrm{s}$; (4) $15 \mu \mathrm{s}$ presented with a dashed line. The jet head developed a "mushroom" form after the target was impacted by the metal jet. Because of different material properties and impact velocities, the jet heads presented different shapes, resulting in different shapes of holes in the target. For the copper

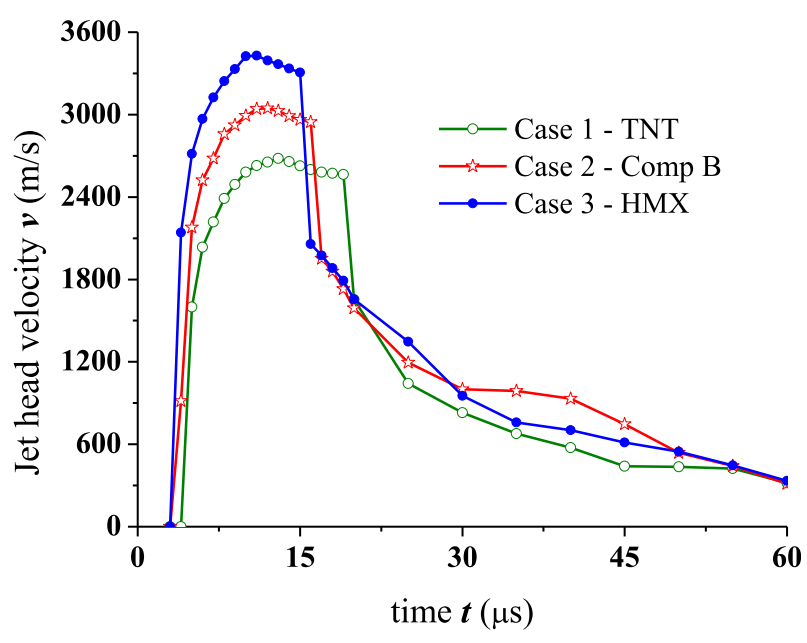

Fig. 4. Evolution of jet-head velocity with time.

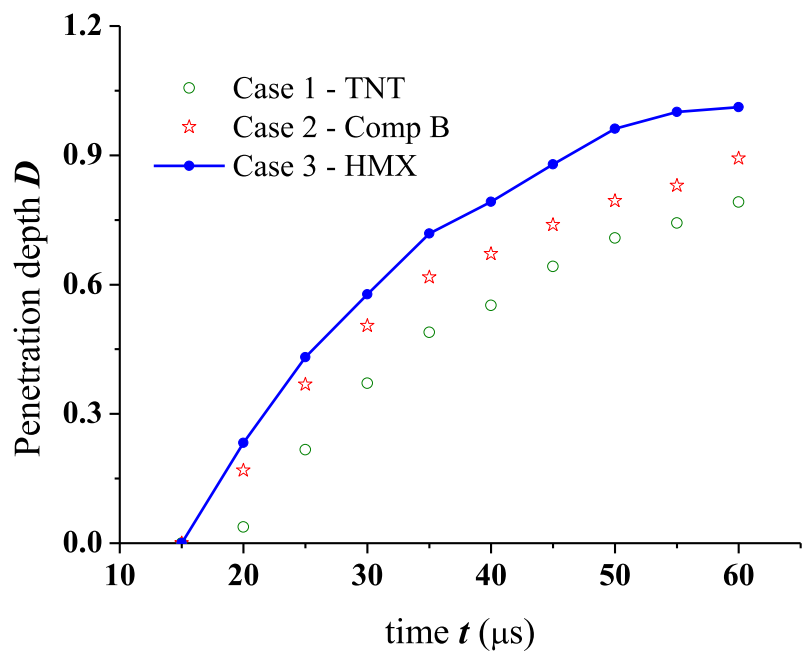

Fig. 5. Evolution of penetration depth with time. 

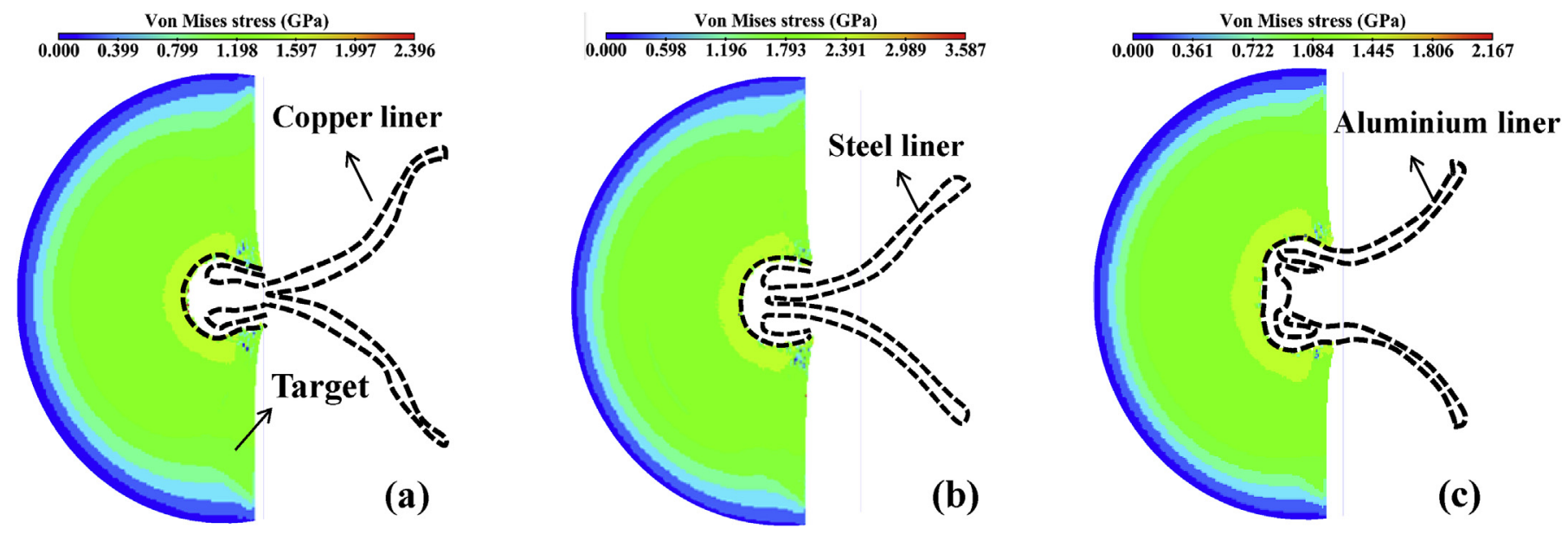

Fig. 6. Distribution of von Mises stress in target. (a)-(c) correspond to Cases 3-5 at $t \approx 60 \mu \mathrm{s}$

liner, the axial penetration depth was somewhat larger than the radial width, and an 'ellipsoidal' hole was formed (Fig. 6(a)). For the steel liner, the shape of the hole was nearly 'spherical' (Fig. 6(b)) due to the same material properties with the target. As for the aluminium liner, Fig. 6(c) shows that the hole had a 'flat' bottom. The reason for this phenomenon was, probably, lower tensile strength of the aluminium liner compared to that of the steel target.

After analysing the jet shape, the results for the jet-head velocity were compared (see Fig. 7). Three cases had the already observed tendency: the velocity rose initially, declining after a peak; subsequently, a sharp decrease was caused when the metal jet began to impact the target; finally, the velocity stabilized. The peak value in Case $5(5203 \mathrm{~m} / \mathrm{s})$ was much larger than that in Cases $3(3430 \mathrm{~m} / \mathrm{s})$ and $4(3547 \mathrm{~m} / \mathrm{s})$. Besides, after the target was impacted by the metal jet, the decrease rate in Case 5 was much higher than that in the other two cases. This could be attributed to lower tensile strength and the ductility of aluminium than that of copper and steel. Meanwhile, the decrease rate in Case 3 appeared smaller than that in Case 4 because copper has a higher tensile strength than steel. Additionally, the level of velocity in Case 3 was larger than that in two other cases after the metal jet arrived at the target, which indicates that a larger penetration velocity may lead to a larger penetration depth.

Although the penetration depth and width are both significant factors for target penetration, for three cases discussed in this manuscript, the results for the penetration width are similar, yet those for

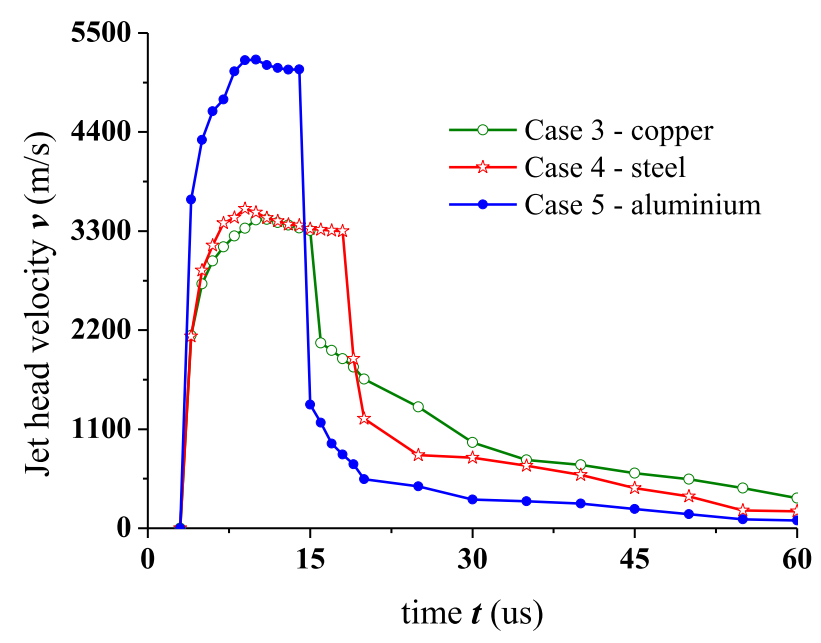

Fig. 7. Evolution of jet-head velocity with time. the penetration depth are quite different. Besides, when the metal jet impacts the warship, especially the double-hull, the penetration depth is more significant since the jet may further damage inner shell, cabins or equipment after it penetrates the outer shell. Hence, the penetration depth is regarded as the damage level, which is discussed in following section. Evolution of the penetration depth with time for three liner materials is shown in Fig. 8. After the metal jet impacted the target, a high-pressure region generated at the contact with stresses in the target exceeding its yield strength; as a result, plastic deformation was caused. So, impact resulted in a hole. Although the jet in Case 5 reached the target earlier than in two other cases, the penetration was shallower. It indicates that the higher velocity does not always result in a more serious damaging effect and the material property should be considered as well. As Fig. 8 shows, the depth increased with time. At about $60 \mu \mathrm{s}$, the depths $D$ respectively rose to $1.01,0.91$ and 0.56 for the three cases; apparently, the depth in Case 3 was the largest. Obviously, the shaped charge with the copper liner had a higher damaging effect on the target.

\subsection{Simulations of metal-jet penetration}

\subsubsection{Numerical verification}

At the next stage, a model of free-field underwater explosion was developed in order to verify the validity of the SPH method in solving

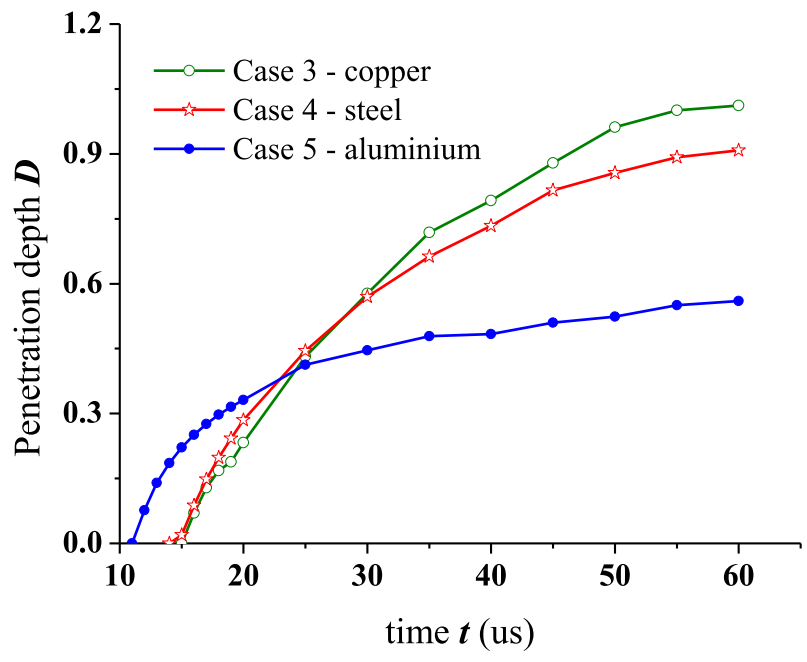

Fig. 8. Evolution of penetration depth with time. 


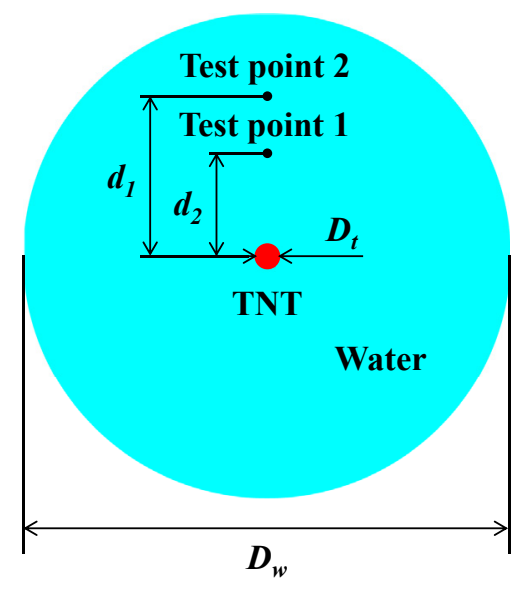

Fig. 9. Model of free-field underwater explosion.

problems with a large density ratio, as shown in Fig. 9. The explosion center is located at the center of the TNT charge which has a diameter $D_{t}=4 \mathrm{~mm}$ in the water with a diameter $D_{w}=160 \mathrm{~mm}$. The distances from the explosion center to test points 1 and 2 are $d_{1}=50 \mathrm{~mm}$ and $d_{2}=40 \mathrm{~mm}$. To study the effect of discretisation, the spacing values of particles were $d_{x}=0.1 \mathrm{~mm}, 0.2 \mathrm{~mm}, 0.3 \mathrm{~mm}$ and $0.4 \mathrm{~mm}$.

The obtained numerical results were compared with those based on Zamyshlyayev's formula (Zamyshlyayev and Yakovlev, 1973) in Fig. 10, where (a) and (b) correspond to test points 1 and 2 in Fig. 9. It was found that the trends of pressure-time curves obtained with the SPH method were similar to that described by the empirical formula, with an error less than $9 \%$ when $d_{x}$ was lower than $0.4 \mathrm{~mm}$. However, there are serious numerical oscillations in the case with $d_{x}=0.4 \mathrm{~mm}$. On the other hand, the case where $d_{x}=0.1 \mathrm{~mm}$ required a significantly larger amount of computations than the case with $d_{x}=0.2 \mathrm{~mm}$. Hence, $0.2 \mathrm{~mm}$ was chosen as the spacing value of particles. The figure also shows that curves in cases with $d_{x}=0.3 \mathrm{~mm}$ and $d_{x}=0.2 \mathrm{~mm}$ are basically consistent. It indicates that the calculated value gradually converged with the decrease in the spacing of particles. Besides, the numerical curves were smooth, verifying the stability of the method. Additionally, the agreement of numerical results with the empirical formula from (Zamyshlyayev and Yakovlev, 1973) proved the effectiveness and feasibility of the presented SPH method in solving problems with a large density ratio.

\subsubsection{Numerical model}

According to the preliminary studies in the above section, the shaped charge with HMX and the copper liner were found to result in the greatest effect of damaging the target. Hence, they were chosen as the explosive and the liner material to investigate the entire physical process - from the charge detonation to the penetration of the metal jet into an underwater plate. The detailed models are shown in Fig. 11, while dimensions of the shaped charge are given in Fig. 2 . The length and width of the water area were $l_{a}=l_{b}=140 \mathrm{~mm}$ when the plate was exposed to water on its back side while the length is $l_{d}=122 \mathrm{~mm}$ when it was exposed to air. The plate was located in the water area about $l_{c}=20 \mathrm{~mm}$ from the charge, with
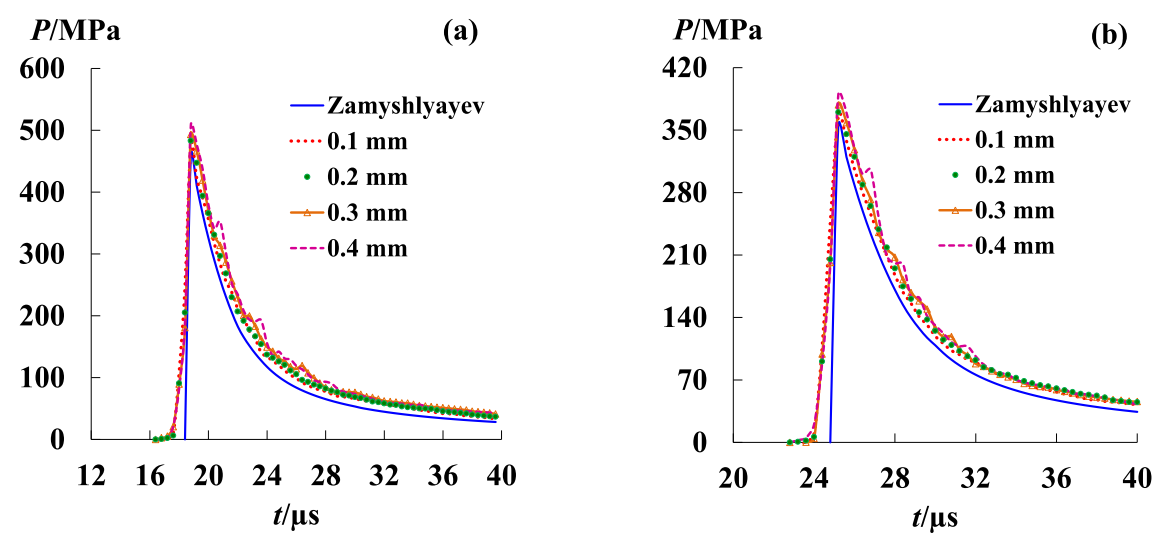

Fig. 10. Pressure-time curves for different particle spacings: (a) test point 1; (b) test point 2.
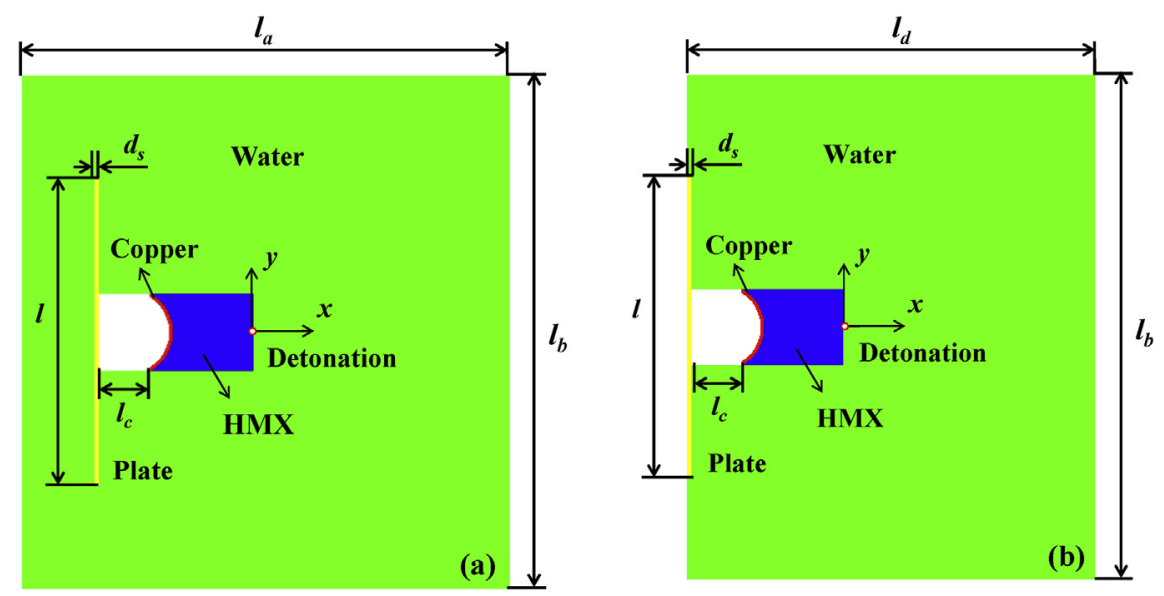

Fig. 11. Models of shaped charge subjected to underwater explosion. (a) and (b) correspond to models of plates exposed on back side to air and water, respectively. 

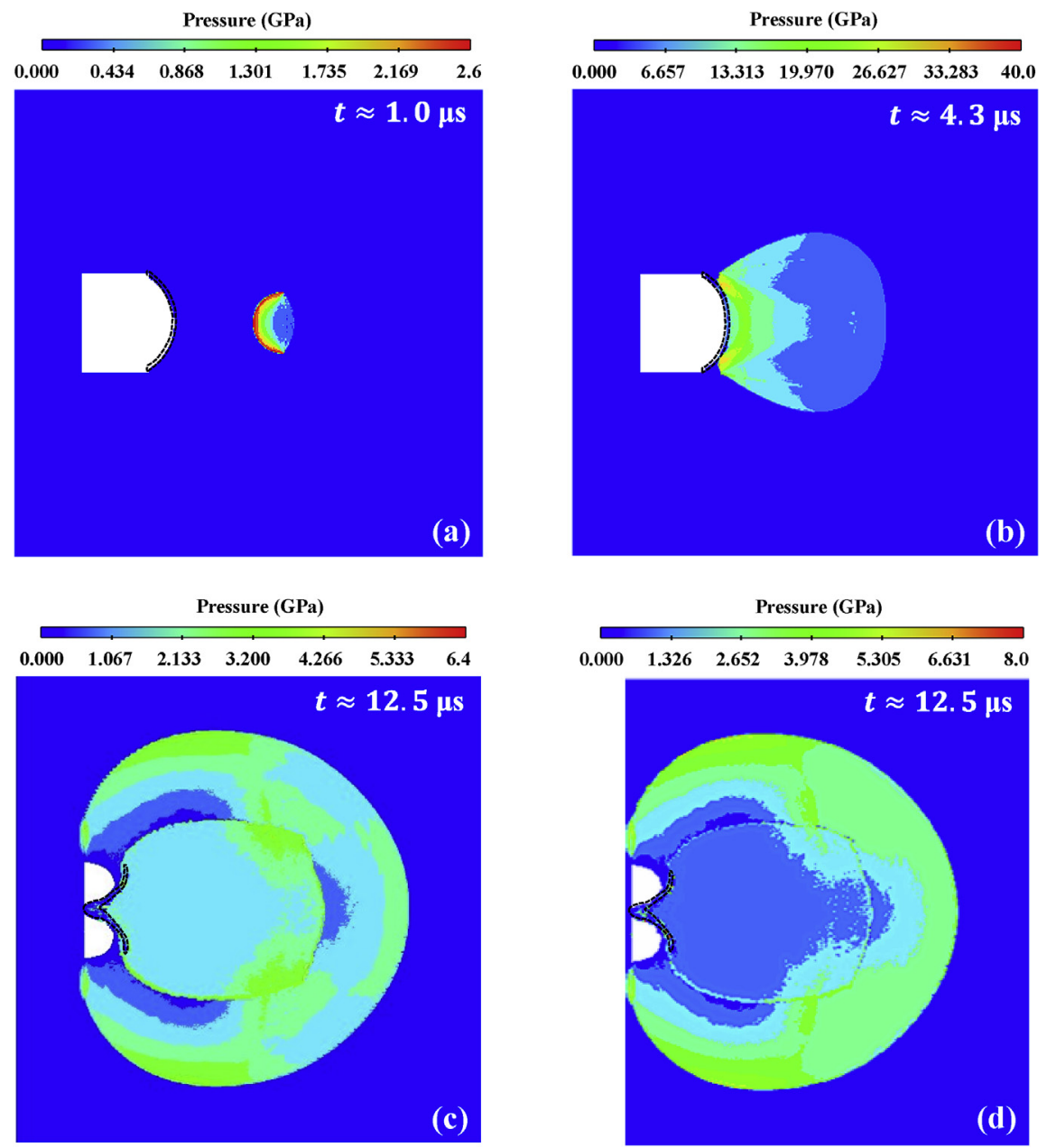

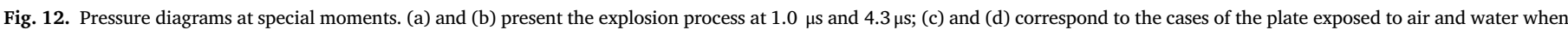
the shock wave arrived at the plate at $12.5 \mu$ s. The region marked with a dotted line presents the shape of the liner.

$l=120 \mathrm{~mm}$ in length and $d_{s}=2 \mathrm{~mm}$ in width. The analysed problems with plates exposed to water and air on their back side correspond to Cases 6 and 7, respectively.

\subsubsection{Shock-wave propagation}

The pressure distributions calculated for different conditions are shown in Fig. 12. The pressure peak value instantaneously reached several gigapascals when the explosive was detonated at $1.0 \mu \mathrm{s}$ (Fig. 12(a)). In the meantime, a spherical detonation wave generated in the explosive and a shock wave were produced in the water. Besides, due to the lower surge impedance, the propagation velocity of the shock wave in the water was lower than that in the explosive. Subsequently, the shock wave reached the liner, and a rarefaction wave was generated and propagated in the detonation products (Fig. 12(b)) because the surge impedance of copper was higher than that of the HMX. After that, the shock wave continued to propagate in the water and reached the plate at $12.5 \mu \mathrm{s}$. It can be observed in Fig. 12(c) that not only a shock wave was generated in the plate, but also a compression wave produced in the water to the right of the plate as well as a transmitted wave was generated in the water to its left. Besides, the left shock wave lagged slightly behind the right one. As for Case 7, Fig. 12(d) shows that the rarefaction wave was reflected when the shock wave propagated to the plate. In addition, Figs. 12(c) and (d) also show that the shock wave did damage to the plate earlier than the metal jet.

Figs. 13 and 14 show pressure distributions and curves at test points 3 and 4 located in the water to the right (front water) and left (back water) of the plate. The origin is located at the detonation point in Fig. 11; the coordinates for two points are $x=-40 \mathrm{~mm}, y=50 \mathrm{~mm}$ and

\section{Pressure (GPa)}

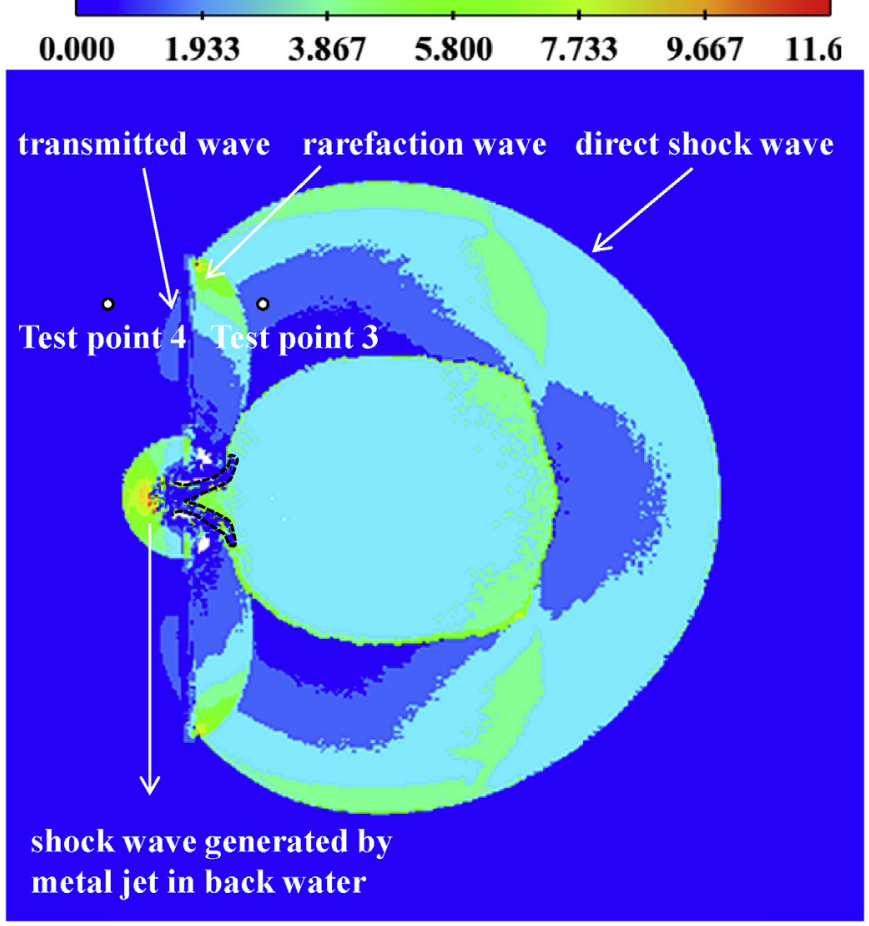

Fig. 13. Pressure diagrams at about $14.0 \mu \mathrm{s}$ 


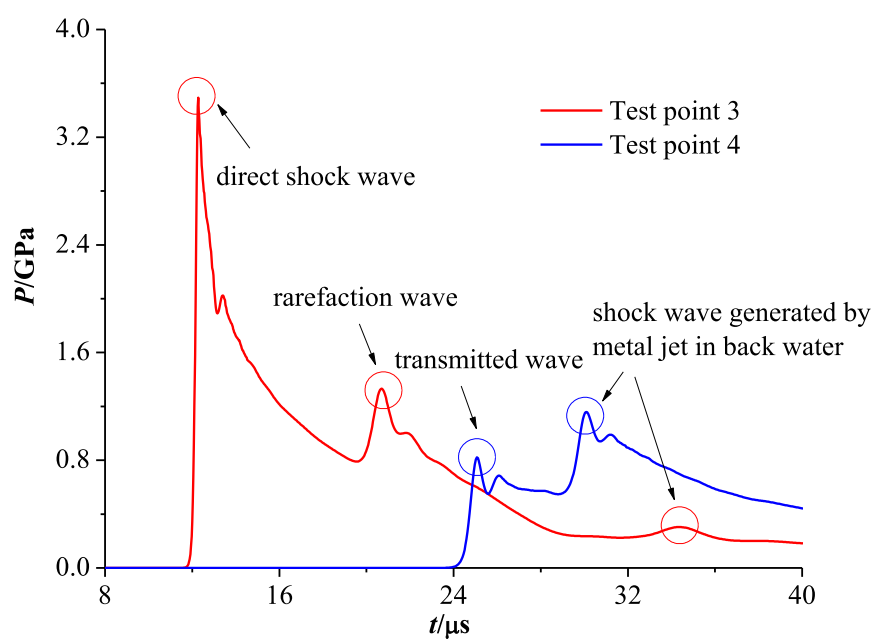

Fig. 14. Pressure curves at test points 3 and 4.

$x=-82 \mathrm{~mm}, y=50 \mathrm{~mm}$, respectively. It can be observed in Fig. 13 that the direct shock wave arrived at test point 3 , causing the first peak at point 3 in Fig. 14. After that, not only a rarefaction wave was generated in the water to the right of the plate but also a transmitted wave produced in the water to its left, resulting in the second peak at point 3 and the first peak at point 4 . Besides, a shock wave was generated in the back water after the metal jet impacted the plate, leading to the second peak at point 4 . After the shock wave reached the plate, a transmitted wave was generated in the front water, which resulted in the third peak at point 3 .

\subsubsection{Metal-jet penetration}

Distributions of von Mises stress for the liner and the plate exposed to air and water at its back side are shown in Fig. 15 for different stages of the jet penetration into it. Obviously, the metal jet began to impact the steel plate and a stress pressure generated in the plate with the stress values up to about $1.61 \mathrm{GPa}$ and $1.97 \mathrm{GPa}$ for Cases 6 and 7, respectively (Figs. 15(a) and (c)). Meanwhile, the jet head was slightly flattened. The plate was penetrated, and a hole was produced (Figs. 15(b) and (d)) at about $14.8 \mu \mathrm{s}$. Then, the stress values diminished to about $1.39 \mathrm{GPa}$ and $1.67 \mathrm{GPa}$, respectively, indicating that the plate exposed to air might be damaged more seriously than that exposed to water. The figures also show that the plastic deformation was caused by the shock wave. In addition, it is obvious that the jet-head shape for Case 6 attained a 'spherical' shape while it was flat for Case 7. The region close to the hole deformed in a direction opposite to the jet velocity.
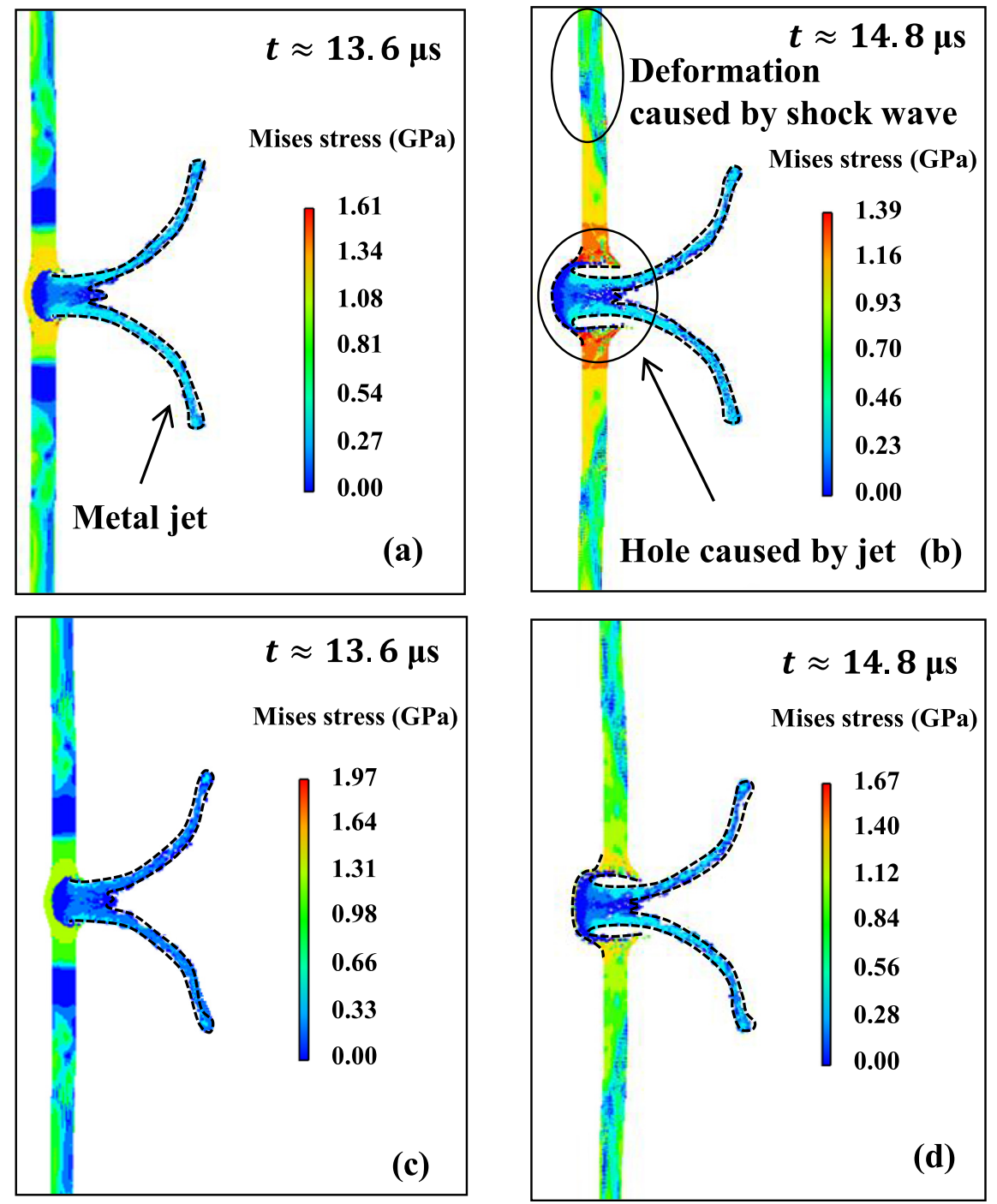

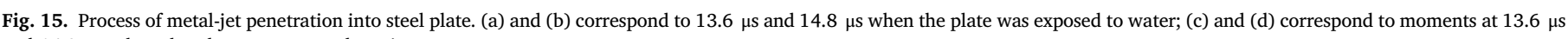
and $14.8 \mu$ s when the plate was exposed to air. 
Table 8

Comparison of results (in $\mathrm{mm}$ ) at $14.8 \mu$ s for plates exposed to water and air.

\begin{tabular}{lll}
\hline & $\begin{array}{l}\text { Case } 6 \\
\text { Plate exposed } \\
\text { to water }\end{array}$ & $\begin{array}{l}\text { Case 7 } \\
\text { Plate exposed } \\
\text { to air }\end{array}$ \\
\hline Maximum deflection & 0.425 & 0.468 \\
Maximum hole diameter & 6.309 & 6.312 \\
Hole diameter on the front side of plate & 5.387 & 5.487 \\
Hole diameter on the back side of plate & 6.251 & 6.304 \\
\hline
\end{tabular}

The detailed comparison of results in Cases 6 and 7 are listed in Table 8. The deflection caused by the shock wave in Case 6 was larger than that in Case 7, which corresponds to the pressure profiles shown in Figs. 12(c) and (d), respectively. The deflection in Case 6 is about 1.1 times larger than that in Case 7 since the water backed plate may provide resistance and absorbed energy to the shock wave. The energy of the transmission shock wave in air for Case 6 is lower, and more energy was converted into the kinetic energy of the plate than that for Case 7. As for the hole caused by the metal jet, the damage zone in Case 7 was somewhat larger than that in Case 6 . This phenomenon was probably caused by a higher von Mises stress in the plate exposed to air. Consequently, the attained results indicate that the plate exposed to air was damaged more seriously, and the water on the back of the plate had a certain protective effect on it.

\section{Conclusions}

A modified smoothed particle hydrodynamics (SPH) scheme was utilized to solve the problem of interfaces with a high density ratio. This modified SPH scheme demonstrated its suitability to simulate complex processes of interaction of a shaped charge with a metallic target. In this study, an SPH model of the shaped charge penetrating a target was developed to investigate effects of different explosives and liner materials on the cumulative effect, and, as a result, the optimal parameters of the model were obtained. Finally, the entire process - from charge detonation to metal-jet penetration into the plate exposed to air or water - was studied based on the analysis of load characteristics. The conclusions can be drawn as follows:

(1) For three studied explosives, HMX resulted in a higher jet-head velocity and had a stronger damaging effect on the target than TNT and Composition B, which may lead to stronger damage on the target.

(2) As for different liner materials, though the jet-head velocity in the case with the aluminium liner was higher than that for the other two cases, its penetration velocity was decreased quickly due to the lower tensile strength and the easier expansion, so that its penetration depth was smaller for a given charge energy. Inversely, the shaped charge with the copper liner kept a larger penetration velocity, it resulted in a larger penetration depth and greater damage to the target. The explosives had little effect on the shape of the metal jet, yet the liner materials influenced it significantly.

(3) On the basis of the comparison for the obtained numerical results, more suitable parameters of the shaped charge - HMX and copper were chosen respectively as the explosive and the liner material are used to simulate the metal jet associated with underwater explosion and its penetration into a plate. It was found that when the shock wave reached the plate, it was reflected due to the relatively higher impedance of steel; plastic deformation of the plate was caused by the direct shock wave first, and then the hole was produced by the metal jet.

(4) The deflection and the hole of plates are respectively caused by the shock wave and the metal jet. The deflection of the water backed plate is about 1.1 times larger than that of the air backed plate. The hole diameter of the water backed plate is somewhat larger than that of the air backed plate. These comparison results indicate that the plate exposed to air at its back side was damaged more seriously than that exposed to water.

\section{Acknowledgment}

This work is supported by the National Natural Science Foundation of China (51479041, 51679044, 51609049) and the Fundamental Research Funds for the Central Universities (HEUCFJ170109).

\section{References}

Allahdadi, F.A., Carney, T.C., Hipp, J.R., Libersky, L.D., Petschek, A.G., 1993. High strain lagrangian hydrodynamics a three dimensional SPH code for dynamic material response. J. Comput. Phys. 109, 67-75.

Arnold, W., Rottenkolber, E., 2013. High explosive initiation behavior by shaped charge jet impacts. Procedia Eng. 58, 184-193.

Baêta-Neves, A.P., Ferreira, A., 2015. Shaped charge simulation using SPH in cylindrical coordinates. Eng. Comput. 32 (2), 370-386.

Børvik, T., Langseth, M., Hopperstad, O.S., Malo, K.A., 1999. Ballistic penetration of steel plates. Int. J. Impact Eng. 22, 855-886.

Chen, Q.Y., Liu, K.X., 2012. A high-resolution Eulerian method for numerical simulation of shaped charge jet including solid-fluid coexistence and interaction. Comput. Fluids 56, 92-101.

Colagrossi, A., Landrini, M., 2003. Numerical simulation of interfacial flows by smoothed particle hydrodynamics. J. Comput. Phys. 191, 448-475.

Dobratz, B.M., 1981. LLNL Explosive Handbook: Properties of Chemical Explosives and Explosives and Explosive Simulants. Report UCRL-52997. Lawrence Livermore National Laboratory, Livermore, CA (USA).

Feng, D.L., Liu, M.B., Li, H.Q., Liu, G.R., 2013. Smoothed particle hydrodynamics modeling of linear shaped charge with jet formation and penetration effects. Comput. Fluids $86,77-85$.

Ghoshal, R., Mitra, N., 2016. Underwater explosion induced shock loading of structures: influence of water depth, salinity and temperature. Ocean. Eng. 126, 22-28.

Han, R., Li, S., Zhang, A.M., Wang, Q.X., 2016. Modelling for three dimensional coalescence of two bubbles. Phys. Fluids 28 (6), 707-721.

Hayhurst, C.J., Clegg, R.A., 1997. Cylindrically symmetric SPH simulations of hypervelocity impacts on thin plates. Int. J. Impact Eng. 20 (1), 337-348.

Hung, C.F., Hsu, P.Y., Hwang-Fuu, J.J., 2005. Elastic shock response of an air-backed plate to underwater explosion. Int. J. Impact Eng. 31, 151-168.

Hung, C.F., Lin, B.J., Hwang-Fuu, J.J., Hsu, P.Y., 2009. Dynamic response of cylindrical shell structures subjected to underwater explosion. Ocean. Eng. 36, 564-577.

Johnson, G.R., Cook, W.H., 1983. A constitutive model and data for metals subjected to large strains, high strain rates and high temperatures. In: Proc. 7th International Symposium on Ballistics, USA.

Johnson, G.R., Cook, W.H., 1985. Fracture characteristics of three metals subjected to various strains, strain rates, temperatures and pressures. Eng. Fract. Mech. 21, 31-48.

Katayama, M., Kibe, S., 2001. Numerical study of the conical shaped charge for space debris impact. Int. J. Impact Eng. 26, 357-368.

Katayama, M., Kibe, S., Yamamoto, T., 2001. Numerical and experimental study on the shaped charge for space debris assessment. Acta Astronaut. 48 (5), 363-372.

Kim, J.H., Shin, H.C., 2008. Application of the ALE technique for underwater explosion analysis of a submarine liquefied oxygen tank. Ocean. Eng. 35 (8), 812-822.

Li, S., Han, R., Zhang, A.M., 2016. Nonlinear interaction between a gas bubble and a suspended sphere. J. Fluids Struct. 65, 333-354.

Liu, G.R., Liu, M.B., 2003. Smoothed Particle Hydrodynamics - a Meshfree Particle Method. World Scientific Publishing Co. Pte. Ltd, Singapore.

Liu, M.B., Liu, G.R., 2010. Smoothed particle hydrodynamics (SPH): an overview and recent developments. Archives Comput. Methods Eng. 17, 25-76.

Liu, M.B., Liu, G.R., Zong, Z., Lam, K.Y., 2003. Computer simulation of high explosive explosion using smoothed particle hydrodynamics methodology. Comput. Fluids 32, 305-322.

Ming, F.R., Zhang, A.M., Xue, Y.Z., Wang, S.P., 2016. Damage characteristics of ship structures subjected to shockwaves of underwater contact explosions. Ocean. Eng. $117,359-382$

Ming, F.R., Sun, P.N., Zhang, A.M., 2017. Numerical investigation of rising bubbles bursting at a free surface through a multiphase SPH model. Meccanica 52, 2665-2684.

Miyoshi, H., 2008. Numerical simulation of shaped charges using the SPH solver: jet formation and target penetration. Mater. Sci. Forum 566, 65-70.

Molinari, J.F., 2002. Finite element simulation of shaped charges. Finite Elem. Anal. Des. 38, 921-936.

Monaghan, J.J., 1994. Simulating free surface flows with SPH. J. Comput. Phys. 110, 399-406.

Rajendran, R., Narasimhan, K., 2001. Performance evaluation of HSLA steel subjected to underwater explosion. J. Mater. Eng. Perform. 10, 66-74.

Rajendran, R., Narasimhan, K., 2006. Deformation and fracture behaviour of plate specimens subjected to underwater explosion - a review. Int. J. Impact Eng. 32, 1945-1963.

Steinberg, D.J., 1987. Spherical Explosions and the Equation of State of Water. Lawrence Livermore National Laboratory. Report UCID-20974. Lawrence Livermore National Laboratory, Livermore, CA (USA). 
Sun, P.N., Colagrossi, A., Marrone, S., Zhang, A.M., 2016. Detection of lagrangian coherent structures in the SPH framework. Comput. Methods Appl. Mech. Eng. 305 (15), 849-868.

Sun, P.N., Colagrossi, A., Marrone, S., Zhang, A.M., 2017. The Splus-SPH model: simple procedures for a further improvement of the SPH scheme. Comput. Methods Appl. Mech. Eng. 315 (1), 25-49.

Swegle, J.W., Attaway, S.W., 1995. On the feasibility of using smoothed particle hydrodynamics for underwater explosion calculations. Comput. Mech. 17, 151-168.

Yang, G., Fu, Y.K., Zheng, J.M., Hu, D.A., 2016. Simulation of formation and subsequent penetration process of linear shaped charge jets with different liners based on SPH method. J. Vib. Shock 35 (4), 56-61 (in Chinese).

Yin, C.Y., Jin, Z.Y., Chen, Y., Hua, H.X., 2016. Shock mitigation effects of cellular cladding on submersible hull subjected to deep underwater explosion. Ocean. Eng. $117,221-237$.

Zamyshlyayev, B.V., Yakovlev, Y.S., 1973. Dynamic Loads in Underwater Explosion. NTIS. AD-757183.

Zhang, A.M., Liu, Y.L., 2015. Improved three-dimensional bubble dynamics model based on boundary element method. J. Comput. Phys. 294, 208-223.

Zhang, A.M., Zhou, W.X., Wang, S.P., Feng, L.H., 2011. Dynamic response of the noncontact underwater explosions on naval equipment. Mar. Struct. 24, 396-411.

Zhang, A.M., Yang, W.S., Yao, X.L., 2012. Numerical simulation of underwater contact explosion. Appl. Ocean Res. 34, 10-20.

Zhang, A.M., Wang, S.P., Chao, H., Wang, B., 2013. Influences of initial and boundary conditions on underwater explosion bubble dynamics. Eur. J. Mech. B/Fluids 42, 69-91.

Zhang, A.M., Cui, P., Cui, J., Wang, Q.X., 2015. Experimental study on bubble dynamics subject to buoyancy. J. Fluid Mech. 776, 137-160.

Zhang, Z.H., Wang, Y.X., Zhao, H.F., Qian, H.F., Mou, J.L., 2015. An experimental study on the dynamic response of a hull girder subjected to near field underwater explosion. Mar. Struct. 44, 43-60.

Zhang, Z.F., Sun, L.Q., Yao, X.L., Cao, X.Y., 2015. Smoothed particle hydrodynamics simulation of the submarine structure subjected to a contact underwater explosion. Combust. Explos. Shock Waves 51 (4), 502-510.

Zhang, Z.F., Wang, L.K., Silberschmidt, Vadim V., 2017. Damage response of steel plate to underwater explosion: effect of shaped charge liner. Int. J. Impact Eng. 103, 38-49.

Zhang, A.M., Sun, P.N., Ming, F.R., Colagrossi, A., 2017. Smoothed particle hydrodynamics and its applications in fluid-structure interactions. J. Hydrodyn. Ser.B 29 (2), 187-216.

\section{Nomenclature}

$A, B, R_{1}, R_{2}, \omega$ : experimental fitting coefficients

$a$ : volume correction coefficient

$B_{0}, n$ : strain-hardening parameter

$C$ : strain-rate-strengthening coefficient
$C_{0}$ : sound velocity

$C_{s}$ : linear participation coefficient of impact velocity

$C_{v}$ : specific heat

$D$ : damage parameter

$D_{1}, D_{2}, D_{3}, D_{4}, D_{5}$ : constants for damage model

$e$ : internal energy

$e_{0}$ : initial internal energy

$f, a, b$ : set parameters

$f(x)$ : field function

$\langle f(x)\rangle$ : approximated value

$h$ : smoothing length

$i, j$ : pair of interactional particles

$I_{2}$ : second invariant of deviatoric stress tensor

$m:$ mass

$M$ : thermal-softening coefficient

$N$ : number of particles in support domain

$p$ : pressure

$r_{0}:$ cutoff radius

$r_{i j}$ : distance between particles $\mathrm{i}$ and $\mathrm{j}$

$S:$ deviatoric stress tensor

$\dot{S}:$ deviatoric stress rate

$S_{1}, S_{2}, S_{3}$ : fitting coefficients

$S_{s}$ : velocity slope of particles

$t$ : time

$T^{\prime \prime}$ : dimensionless temperature corresponding to current level $\mathrm{T}$

$T_{m}$ : melting point

$T_{r}$ : room temperature

$\nu$ : velocity of particles

$W$ : smooth function

$x$ : displacement of particles

$Y$ : yield strength

$\gamma_{0}:$ Gruneisen coefficient

$\Gamma$ : Gruneisen parameter

$\dot{\varepsilon}_{0}$ : reference strain rate

$\varepsilon_{e}$ : equivalent plastic strain

$\dot{\varepsilon}_{e}$ : equivalent plastic strain rate

$\varepsilon_{f}$ : equivalent strain to fracture

$\Delta \varepsilon$ : increment of equivalent plastic strain

$\eta$ : ratio of density before and after explosion

$\mu$ : compression ratio

$\Pi_{i j}$ : artificial viscosity

$\rho$ : density

$\rho_{0}$ : initial density

$\sigma:$ stress

$\sigma_{0}$ : static yield strength

$\tau$ : viscous shear stress 